\title{
Modeling and Simulation: a Comprehensive and Integrative View
}

\author{
Tuncer I. Ören
}

\section{1}

\section{Introduction}

Compared to other well-established disciplines such as those in the humanities and the social, natural, formal, and applied sciences, modeling and simulation (M\&S) is a relatively new discipline. For example, an important professional society, the Society for Modeling and Simulation International, was only formed in 1952 (SCS, 2008). However, the development of the field has been phenomenal. Currently, there are almost 100 associations and organizations in several aspects of $M \& S$ (M\&S-AO, 2008), and $M \& S$ is successfully used in a range of application areas (Ören, 2009).

Daniel Bell, who promoted the concepts of postindustrial society and information age, also predicted the importance of simulation. In a seminal article, he posited that abstract theories, models, simulations, decision theory, and systems analysis would be the methodologies in postindustrial societies (Bell, 1976). He also said that "the key political problems in a post-industrial society are essentially elements of science policy".

After many success stories in challenging application areas, possibilities are still growing on what one can achieve by proper use of M\&S. At the dawn of the 21st century, as also acknowledged by the US Senate, M\&S is indeed a critical area for the well-being of many advanced countries. The USA adopted House Resolution 487 in 2007 (HR487, 2008). Other countries or unions such as the European Union may benefit from the USA's good example. Taking advantage of the full benefit of model-based simulation as well as complementary model-based activities wait to be tapped and offer opportunities for advanced developments in associated theories, methodologies, and technologies. In other words, decision makers who can perceive the big picture of $M \& S$ will be influential in taking advantage of the opportunities offered by M\&S. This article aims to contribute to the development of a body of knowledge in M\&S. Simulation is based on the concept of similarity, which has a very broad connotation. A list of over 80 terms other than simulation with similar connotations is given in the appendix. 


\section{2}

\section{Simulation: Several Perspectives}

An early list of definitions of simulation was compiled by Pritsker (1979). Currently, many definitions of simulation can be found on the Web (simDefs-Web, 2008), and several hundred more definitions can be found by googling "definition of simulation". Several groups prefer to use narrow definitions of M\&S. For example, version 1.0 of the NATO Modelling and Simulation Master Plan has the following definition of simulation: "The execution over time of models representing the attributes of one or more entities or processes. Human-in-the-Loop simulations, also known as simulators, are a special class of simulations" (NATO-MP-v1.0, 2008). The Canadian Synthetic Environment Coordination Office uses the following definition: "A simulation is the implementation of a model over time" (simDef-SECO, 2008). Some of the definitions are very specific and even circular; for example, the glossary of an administration of the US Department of Health and Human Services defines simulation as follows: "A method of quantifying costs or benefits in which the process is analyzed and simulated to obtain costs" (US-DHaHS, 2008). Other definitions are even incorrect and misleading. For example, in one online dictionary, computer simulation is defined as an "Alternative term for computer modeling" (BD, 2008).

Simulation is used for hundreds of application areas and can be perceived from different perspectives. Most definitions of simulation are representative of this aspect-oriented perception of simulation (simDefs-Web, 2008). In this chapter, the intention is to offer generic definitions that can also be top-down decomposable to explore the rich paradigms that $\mathrm{M} \& \mathrm{~S}$ is associated with. Having a comprehensive and integrative view of $M \& S$ is essential to benefiting from its full potential. As seen in Table 1.1, M\&S can be perceived from the following perspectives: purpose of use, problem to be solved, connectivity of operations, types of knowledge processing, and philosophy of science.

\subsection{1}

\section{Purpose of Use}

Table 1.2 highlights three purposes use of M\&S. As a process, the term simulation has three meanings, two technical and one nontechnical.

As a technical term, two main types of uses of M\&S can be identified. M\&S is used (1) to perform experiments (for decision support, understanding, and education) and (2) to provide experience (for training and entertainment) through controlled conditions. The technical meanings cover any type of simulation regardless of whether or not the simulation is computerized and whether it is carried out on pure software or on any type of hardware/software. Furthermore, both of the technical meanings allow top-down decomposition of the entities and activities involved and thus enable their systematic and hierarchical elaborations. As a nontechnical term, simulation has been used in English since 1340 and means "imitation" or "fake". The explanation in the Online Etymology Dictionary is: "'a false show, false 
Table 1.1 Perception of M\&S from different perspectives.

\begin{tabular}{|c|c|}
\hline Perception with respect to & Perceptions of simulation \\
\hline Purpose of use & $\begin{array}{l}\text { Perform experiments for: } \\
\text { Decision support, Understanding, Education } \\
\text { Provide experience for: } \\
\text { Training, Entertainment } \\
\text { Imitation (fake) }\end{array}$ \\
\hline Problem to be solved & $\begin{array}{l}\text { Black box perception (M\&S is an infrastructure to support } \\
\text { real-world activities) }\end{array}$ \\
\hline Connectivity of operations & $\begin{array}{l}\text { Standalone simulation } \\
\text { Integrated simulation (symbiotic simulation) }\end{array}$ \\
\hline Types of knowledge processing & $\begin{array}{l}\text { Computational activity } \\
\text { Systemic activity } \\
\text { Model-based activity } \\
\text { Knowledge generation activity } \\
\text { Knowledge processing activity }\end{array}$ \\
\hline Philosophy of science & $\begin{array}{l}\text { Simulation supports and enriches modern } \\
\text { scientific thinking } \\
\text { [Francis Bacon (Novum Organon, 1620)] }\end{array}$ \\
\hline
\end{tabular}

Table 1.2 Three purposes of use of M\&S.

\begin{tabular}{ll}
\hline Purpose of use of simulation & Type of simulation \\
\hline Perform experiments for: & Simulation \\
- Decision support & \\
- Understanding & \\
- Education & \\
Provide experience (under controlled conditions) for: & \\
- Training (for gaining/enhancing competence): & \\
- motor skills & Virtual simulation \\
- decision and/or communication skills & Constructive simulation \\
- operational skills & Live simulation \\
- Entertainment & Simulation game \\
Imitation & Representation \\
& Fake
\end{tabular}

profession', from O. Fr. [Old French] simulation, from L. [Latin] simulationem (nom. simulatio) 'an imitating, feigning', noun of action from simulare 'imitate', from stem of similis 'like"' (OED-sim, 2008). The definition, from the same dictionary, for the related term simulacrum, which has been in use in English since 1599, is: "from L. simulacrum 'likeness, image, form, representation, portrait', dissimilated from simulaclom, from simulare 'to make like'. The word was borrowed earlier as sem- 
ulacre (c. 1375), via O. Fr. simulacre" (OED-simulacrum, 2008). In this chapter, we focus on the technical meanings of the term simulation.

\subsubsection{Experimentation}

In areas other than training and entertainment, simulation is goal-directed experimentation with dynamic models. These areas include decision support, understanding, and education. Experimentation has been one of the key concepts in scientific thinking ever since Francis Bacon (1561-1626) advocated it in 1620 in his Novum Organum (New Instrument). Bacon's work was a categorical departure from and reaction to the Organon (The Instrument), which was the title given to Aristotle's (384-322 BC) logical works, which itself had an unparalleled influence on the history of Western thought (Ören, 2002). Hence, the technical definition related to experiments also ties simulation to the origins of modern scientific thinking. However a programmer's view of simulation would be biased to the execution of the simulation program and would hinder this important point. The advantage of performing the experiments on a model rather than on the real system is also well established.

Use of Simulation for Decision Support As outlined in Table 1.3, the use of simulation for decision support includes its use for prediction (of behavior and/or performance), evaluation of alternatives, sensitivity analysis, evaluation (of behavior and/or performance) of engineering design, virtual prototyping, testing, planning, acquisition, and proof of concept.

Use of Simulation for Understanding In analysess of mostly natural problems, simulation is a very powerful technique used to understand them. Several models can be tested until the behaviors of the model and the real system match under the same or very similar conditions. Understanding has several connotations. The meanings of understanding in machine understanding are applicable for

Table 1.3 Three purposes of use of M\&S.

Prediction of behavior and/or performance of the system of interest within the constraints inherent in the simulation model (e.g., its granularity) and the experimental conditions

Evaluation of alternative models, parameters, experimental and/or operating conditions on model behavior or performance

Sensitivity analysis of behavior or performance of the system of interest based on granularities of different models, parameters, experimental and/or operating conditions

Evaluation of behavior and/or performance of engineering designs

Virtual prototyping

Testing

Planning

Acquisition (or simulation-based acquisition)

Proof of concept 
simulation-based understanding. In Ören et al. (2007), nearly 60 types of machine understanding are presented in an ontology-based dictionary.

Use of Simulation for Education Simulation provides an excellent laboratory in teaching any type of dynamic system. A bibliography related to the classroom use of simulation has been prepared by O'Haver (2008). The site http://www.site.uottawa. ca/ oren/MSBOK/sim4Ed.htm (sim4Ed, 2008), though dated, contains links to several reference books, articles, and theses as well as many demonstration software resources and individual software in teaching areas such as acoustics; electricity, electronics, magnetism; energy, heat, thermodynamics; fluid dynamics; mathematics; mechanics; nuclear physics; optics; oscillations and waves; plasma physics; quantum physics; radiation; relativity; sound; superconductivity; and theoretical physics. Some portals and additional links can also be found.

\subsubsection{Experience (for Training and Entertainment)}

As outlined in Table 1.2, in training, simulation is used to gain/enhance competence through experience under controlled conditions. Three major types of simulation correspond to three types of training.

1. Virtual simulation (i. e., use of simulators or virtual simulators) is used to enhance motor skills to gain proficiency of use of equipment such as an airplane, a tank, or a car. In virtual simulation, real people use virtual equipment in virtual environments; hence the term "virtual simulation".

2. Constructive simulation (or gaming simulation such as war gaming, peace gaming, international relations gaming, business gaming, etc.) is used to enhance decision making and/or communication skills. In constructive simulation, simulated people use simulated equipment in a virtual environment and real people get experience by interacting with the simulation system.

3. Live simulation is used to gain/enhance operational skills by getting real-lifelike experience in a controlled environment. Live simulation is used in such diverse areas as military exercises as well as for the training of health specialists. In live simulation, real people use imitation (or virtual or dummy) equipment in the real world.

In entertainment (i. e., simulation games and some types of animation of dynamic systems), simulation provides experience under controlled conditions. "Getting experience under controlled conditions" is the common aspect in using M\&S for training (i.e., gaining/enhancing competence) as well as for entertainment purposes. The term "serious game" is used to distinguish simulation games used in areas other than entertainment.

\subsubsection{Imitation}

As explained in Section 1.2.1, since the 14th century, the term "simulation" has been used to denote an imitation, a representation, something similar; when the dissimilarity was deceitful, then the term "simulation" was used to mean fake". For 
example, "simulated leather" means "imitation leather". Sometimes, "to simulate" is used in the sense of "to pretend". The French postmodern theorist Jean Baudrillard (1929-2007) is well known for elaborating on the interaction of reality and symbols in postmodern society, particularly in his Simulacra and Simulation (Simulacres et Simulation in French) (Baudrillard, 1985). Simulacrum, the singular form of simulacra, means (1) an image or representation; (2) an unreal or vague semblance. However, Baudrillard uses the term simulacra to mean "the copy without an original". Understanding "hyperreality" may be helpful to clarify some concepts. "Hyperreality is closely related to the concept of the simulacrum: a copy or image without reference to an original. In postmodernism, hyperreality is the result of the technological mediation of experience, where what passes for reality is a network of images and signs without an external referent, such that what is represented is representation itself" (SEP-postmodernism, 2008).

For Baudrillard, modern societies are organized around the production and consumption of commodities, while postmodern societies are organized around simulation and the play of images and signs, denoting a situation in which codes, models, and signs are the organizing forms of a new social order where simulation rules. In the society of simulation, identities are constructed by the appropriation of images, and codes and models determine how individuals perceive themselves and relate to other people. Economics, politics, social life, and culture are all governed by the mode of simulation, whereby codes and models determine how goods are consumed and used, politics unfold, culture is produced and consumed, and everyday life is lived. In addition, Baudrillard's postmodern universe is one of hyperreality in which entertainment, information, and communication technologies provide experiences more intense and involving than the scenes of banal everyday life, as well as the codes and models that structure everyday life. The realm of the hyperreal (e. g., media simulations of reality, Disneyland and amusement parks, malls and consumer fantasylands, TV sports, and other excursions into ideal worlds) is more real than real, whereby the models, images, and codes of the hyperreal come to control thought and behavior. Yet determination itself is aleatory in a nonlinear world where it is impossible to chart causal mechanisms in a situation in which individuals are confronted with an overwhelming flux of images, codes, and models, any of which may shape an individual's thought or behavior (SEP-Baudrillard, 2008).

\section{2 .2}

\section{Problem to Be Solved}

With respect to the problem to be solved, a perception of M\&S is that it is as an infrastructure to support real-world activities. This is the black box perception by practitioners, who would like to emphasize that simulation is a tool to achieve other goals. This view allows concentrating on the original problems they face; for 
example, for NASA the goal is successful space missions and not simulation; likewise for the military, similarly and justifiably, the goal is not simulation. From this perspective, simulation is perceived as not being the "real thing". This attitude is well documented in STRICOM's motto: "All but war is simulation" (STRICOM, 2008). This view can lead to successful applications of simulation in familiar areas. However, a broader view of M\&S can lead to better appreciation of the full scope of possibilities that simulation offers. Hence, the limitations of this black box perception of simulation are: (1) not even wanting to know what one misses and (2) to be obliged to have "patches" in the conception of M\&S when the need arises instead of benefiting from a comprehensive and integrative view.

\section{2 .3}

\section{Connectivity of Operations}

As seen in Table 1.4, two important categories of simulation can be distinguished with respect to the connectivity of operations of simulation and the system of interest. They are: standalone simulation and integrated (or symbiotic) simulation. In standalone simulation, operations of the simulation and the system of interest are independent, that is, are not connected. The majority of simulations belong to this category. In integrated (or symbiotic) simulation, operations of the simulation and the system of interest are interwoven. In integrated simulation, simulation enriches or supports real-system operation. To enrich operations of the real system, the system of interest and the simulation program operate simultaneously to assure online diagnosis or augmented reality (enhanced reality) operation. To support operations of the real system, the system of interest and the simulation program operate alternately to provide predictive displays. Predictive displays are based on parallel experiments while the system is running.

\section{2 .4}

\section{M\&S as a Type of Knowledge Processing}

Simulation can be seen as a type of knowledge processing at different levels of abstraction (Table 1.1). Hence, simulation can be perceived as a computational activity, systemic activity, model-based activity, knowledge generation activity, or knowledge processing activity.

\subsubsection{M\&S as a Computational Activity}

The role of the computer in simulation spans from the generation of model behavior to simulation-based problem-solving environments. Some definitions of simulation, for example, the execution over time of models representing the attributes of one or more entities or processes, concentrate on the lowest level of computerization activity. This computational view of execution of a simulation program may hinder the high-level possibilities of simulation-based computer-aided problemsolving environments such as computer-aided problem specification, model speci- 
Table 1.4 Types of M\&S with respect to the connectivity of operations of simulation and the system of interest.

Type of
connectivity

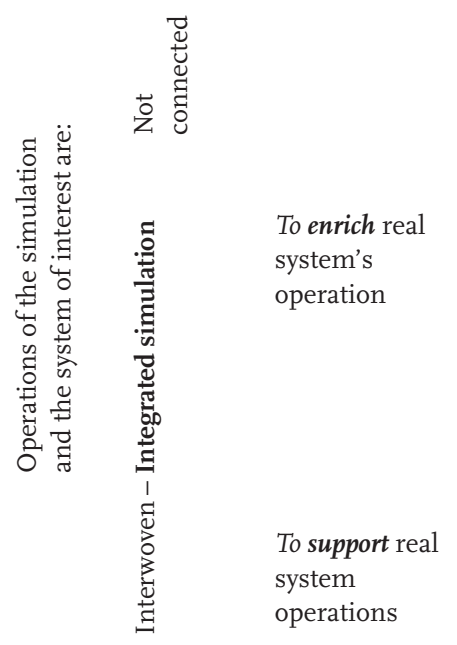

Standalone simulation

(The system of interest and the simulation program operate simultaneously)

- online diagnostics (or simulation-based diagnostics)

- simulation-based augmented/enhanced reality operation (for training to gain/enhance motor skills and related decision making skills)

(The system of interest and the simulation program operate alternately to provide predictive displays)

- parallel experiments while system is running

fication (model synthesis, model composition), model transformation, experimental frame specification (design and execution of experiments, as well as analyses of the results of the experiments), program generation, and symbolic processing of problem specifications to assure built-in quality. The concept of high-level computer assistance in M\&S has been promoted since the early 1980s (Ören, 1982).

\subsubsection{M\&S as a Systemic Activity and System Theory-Based Simulation}

From a systemic point of view, simulation can be used to find the values of output, input, or state variables of a system, provided that the values of the two other types of variables are known (Table 1.5). The state represents the structure of the system, that is, state variables, state transition function, and output functions.

In an analysis problem, the system is given. A model can be constructed to represent the system of interest. Hence the state variables are known. In a simulation run, the model is driven with a behavior generator under the experimental conditions to generate model behavior (output). In a design problem, input-output pairs are given as part of the design requirements; the problem is finding the state variables that may satisfy the input-output pairs. For a given design, hence a model to represent it, the state is given. Hence simulation runs can be performed with the given inputs until input-output pairs are satisfied. Then the state variables used cor- 
Table 1.5 Three types of system problems.

\begin{tabular}{|c|c|c|c|}
\hline \multirow{2}{*}{$\begin{array}{l}\text { System } \\
\text { problems }\end{array}$} & \multicolumn{3}{|c|}{ Three types of system knowledge } \\
\hline & Inputs & States & Outputs \\
\hline Analysis & (given) & (given) & find \\
\hline Design & (given) & find & (given) \\
\hline Control & find & (given) & (given) \\
\hline
\end{tabular}

respond to the desired design. In a control problem, the system, and hence the state, is given along with the desired system behavior (i. e., system output). The problem is to find the necessary input to generate the desired output. Hence, with the given state, simulation runs can be performed until the desired output is obtained. Then the inputs used correspond to the necessary control.

As a very important and fundamental contribution to $M \& S$, system sciences provide the basis for modeling formalisms as well as for symbolic processing of models for a wide variety of dynamic systems. These include automata, cellular automata, Lindenmayer systems (or L-systems), Petri nets, system dynamics, bond graphs, goal-directed systems, variable-structure systems, and evolutionary systems (Ören et al., 1984). Advances in discrete event systems specification (DEVS) by Zeigler (1984) and many valuable variant theories based on DEVS provide a robust theoretical background for the simulation of complex systems modeled as discrete event systems. The first model-specification language based on a system theory (Wymore, 1967) for continuous systems described by differential equations was developed in the early 1970s (Ören, 1971, 1984a). The craftsmanship of a carpenter who can build a summer cottage cannot scale up to build a skyscraper, which requires the appropriate engineering knowledge based on theoretical knowledge. Similarly, to build simulation systems for large and complex problems, systemtheoretic-robust approaches are necessary, especially if one would like to avoid problems at later phases of projects.

\subsubsection{M\&S as a Model-Based Activity}

The perception of simulation as a model-based activity has several advantages; among other possibilities, it allows for the construction of simulation-based computer-aided problem-solving environments (Zeigler et al., 1979; Ören, 1984b; Ören et al., 1984; Elzas et al., 1986, 1989). Currently, several disciplines have adopted model-based paradigms. They include systems engineering (Wymore, 1993), software engineering (mc-swEng, 2008), and model-driven enterprise information systems (md-EIS, 2008). In M\&S, in addition to the generation of model behavior, the following can be considered:

- computer-aided modeling (model composability);

- model-base management (or management of model repositories, including their interfaces) (for reusability); 
- parameter-based management (for example, in nuclear fuel waste management simulation systems, several thousand constants and parameters, some of which are represented as probability distribution functions, have to be managed);

- symbolic processing of models (see the section on model-based activities).

Of course, in M\&S, model-based activities can be best achieved by using an appropriate mathematical system theory.

\subsubsection{M\&S as a Knowledge-Generation Activity}

From an epistemological point of view, simulation is a knowledge generation activity; more specifically, simulation is a goal-directed knowledge generation activity with dynamic models within dynamic environments. This view allows advanced methodologists and technologists to integrate simulation with several other knowledge generation techniques (Ören, 1990). At this abstract level, the definition of simulation can be interpreted as model-based experiential knowledge generation. This abstraction facilitates the synergy of simulation with other knowledge generation (and processing) techniques. Knowledge can be generated with or without models by (experience-based or not) techniques that include instrumentation and experimentation in the real world; any type of simulation; computation, optimization, statistical inferencing, reasoning, hypothesis processing, as well as en-

Table 1.6 Types of simulation-based augmented reality.

\begin{tabular}{|c|c|c|}
\hline \multicolumn{3}{|c|}{ Type of environment (and equipment) } \\
\hline & Real environment & Simulated environment \\
\hline 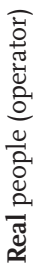 & $\begin{array}{l}\text { Live simulation } \\
\text { Real people operate real and/or simulated } \\
\text { equipment in real environment }\end{array}$ & $\begin{array}{l}\text { Virtual simulation } \\
\text { Real people operate simulated } \\
\text { equipment within virtual } \\
\text { (simulated) environments } \\
\text { - Simulator } \\
\text { - Virtual simulator (All } \\
\text { software simulator) }\end{array}$ \\
\hline 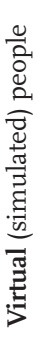 & $\begin{array}{l}\text { Automated vehicles } \\
\text { Automatic control system (virtual operator) } \\
\text { operates real equipment in real environment for } \\
\text { example, vehicle without driver, aircraft without } \\
\text { pilot; auto pilot } \\
\text { Virtual (simulated) training vehicle } \\
\text { Virtual people operate simulated equipment in } \\
\text { real environment for example, virtual (simulated } \\
\text { or AI) aircraft in a dogfight training; virtual tank, } \\
\text { etc. }\end{array}$ & $\begin{array}{l}\text { Constructive simulation } \\
\text { Simulated people use simulated } \\
\text { equipment within simulated } \\
\text { environments to provide } \\
\text { experience to real people }\end{array}$ \\
\hline
\end{tabular}


riched (augmented) reality. Table 1.6 outlines types of simulation-based augmented reality.

In live simulation, simulation as a knowledge generation activity is integrated with the operations of the real system where the real system acts as yet another source for knowledge generation.

\subsubsection{M\&S as a Knowledge-Processing Activity}

This view allows advanced methodologists and technologists to integrate simulation with several model-based activities and several other knowledge processing techniques (Ören, 1990) to generate integrated simulation-based problem-solving environments. In this case, one can combine modeling, model processing, and other knowledge processing engines to have advanced simulation environments. These include integrated use of M\&S with optimization, artificial intelligence, and software agents. In the last case, agents can also be used for additional purposes to assure the quality and reliability of operations. This view also allows for the combination of simulation systems with sensors and affectors. Sensors are energy transducers that transform energy into other types of energy or into information about the input energy that can be inputted to a simulation system. (Energy transducers and their relation to knowledge transducers were introduced by Ören (1990). Inversely, information inputted to an affector is transformed into energy to perform an action that comes about as a result of a deliberative system or a simulation system representing it.

\section{2 .5}

\section{M\&S from the Perspective of Philosophy of Science}

Simulation supports and enriches modern scientific thinking as promoted by Francis Bacon in 1620 in his "Novum Organum" by extending the possibilities for making experiments:

- Simulation allows experimentation (with dynamic models) when experimentation with a real system is not possible or feasible.

- Simulation enriches experimentation by allowing experimentation (with dynamic models) done under conditions not feasible with real systems.

\section{3}

\section{Model-Based Activities}

Model-based activities consist of model building, model-base management, and model processing (Table 1.7).

In software engineering, one of the sources of several types of failures has been the practice of the maintenance of the code, instead of maintenance of the specification. In M\&S, since the early days program generators have existed to generate code from high-level specifications (Mathewson, 1974). In model-based simulation, the 
Table 1.7 Types of model-based activities.

1. Model building

- modeling

- model synthesis

- model composition (and dynamic model composition)

2. Model-base management (and management of model repositories)

- model search

- semantic model search

- model integrity

3. Model processing

- model analysis

- model characterization (descriptive model analysis)

- model evaluation (evaluative model analysis)

- model transformation

- behavior generation (generation of behavior of model)

Table 1.8 Some advantages of model-based simulation.

1. Efficiency in Computerization

- Modelbases (or model repositories) may contain model specifications that can easily be converted into programs. Hence, programming aspect can and should be fully automated.

- This aspect also eliminates programming errors and contributes to the reliability of the computerization of models.

2. Reliability

- Models can easily be read and understood by specialists in the field assuring model reliability.

- Model specifications can be checked by specialized software as well as manually for consistency, completeness, and correctness. This aspect is definitely superior to traditional V\&V techniques that work on code only and can be the basis for built-in reliability in M\&S studies.

3. Reusability and Composability

- Model specifications can easily be modified for model reusability as well as model composition.

- Some of the model composability techniques can be dynamically applicable for systems that not only have dynamic behavior but also can and should be modified dynamically as the simulation evolves.

4. Interoperability

- It is highly desirable to check interoperability of model specifications rather than the codes of models. Executability of code does not necessarily signify its semantic interoperability.

model specification can be transformed into a computer code by a program generator. Some of the advantages of model-based simulation are efficiency, reliability, reusability, and interoperability; they are summarized in Table 1.8 . 
1.3.1

\section{Model Building}

Modeling has long been automated in M\&S. The applications started with filling in questionnaires (Oldfather et al., 1966) and the use of high-level simulation languages. For a review of the early developments see Nance (1983). Graphical modeling is another aspect that is used successfully. However, other possibilities exist for the use of dynamically tailorable templates for advanced modeling (Ören, 1991).

\subsection{2}

\section{Model-Base Management}

Model-base management facilitates the management of model specifications as opposed to the management of computerized expressions of models; hence, it facilitates the efficiency, reliability, reusability, and interoperability of models. Some additional issues are semantic search of models and especially model integrity.

\section{3 .3}

\section{Model Processing}

As shown in Table 1.7, model processing consists of model analysis, model transformation, and behavior generation. From a pragmatic point of view, they can be applicable in model-based simulation where models are expressed in terms of appropriate mathematical systems theories that provide solid methodologies to specify models as well as to process them. The next generation of powerful model-based simulation environments can be realized by an integrative use of several modelbased activities.

\subsubsection{Model Analysis}

There are two types of model analysis: descriptive and evaluative analyses. Descriptive model analysis is model characterization. Evaluative model analysis is model evaluation. As seen in Table 1.9, model characterization consists of model comprehensibility and model usability.

Table 1.10 summarizes model evaluation, or the evaluative analysis of models. Tables 1.11-1.14 outline model evaluation (i.e., evaluative model analysis) with respect to modeling formalisms, another model, real systems, and the goal of the study.

Validity, as a special type of model evaluation, has several types, as shown in Table 1.15. In a glossary of validation, one can list the definitions of each one of the terms given in Table 1.15. However, an ontology-based dictionary for these terms would have two advantages: (1) It can also provide the logical relationships of the terms since it will be based on a classification of the concepts and (2) the terms can be linked from a regular alphabetical list. For examples of ontology-based dictionaries, see Ören (2006) and Ören et al. (2007). 
Table 1.9 Types of descriptive model analysis.

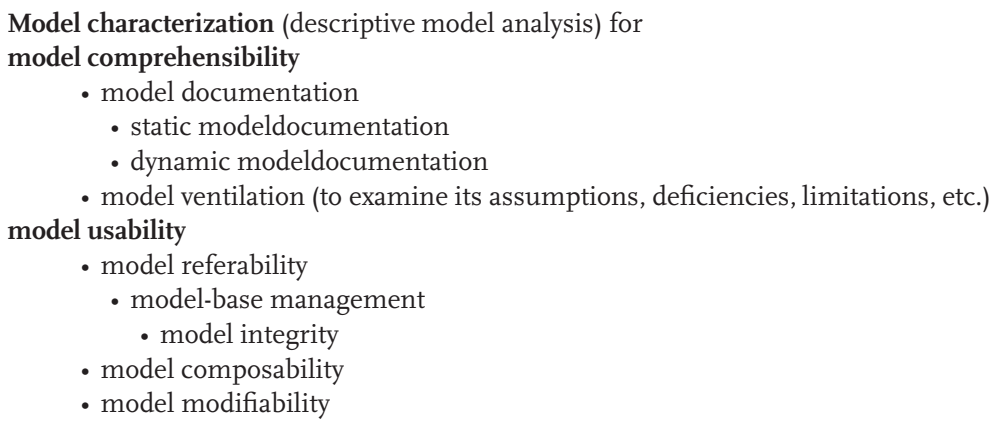

Table 1.10 Types of evaluative model analysis (model evaluation).

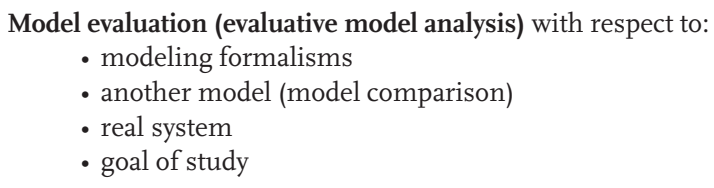

Table 1.11 Types of model evaluation with respect to modeling formalisms.

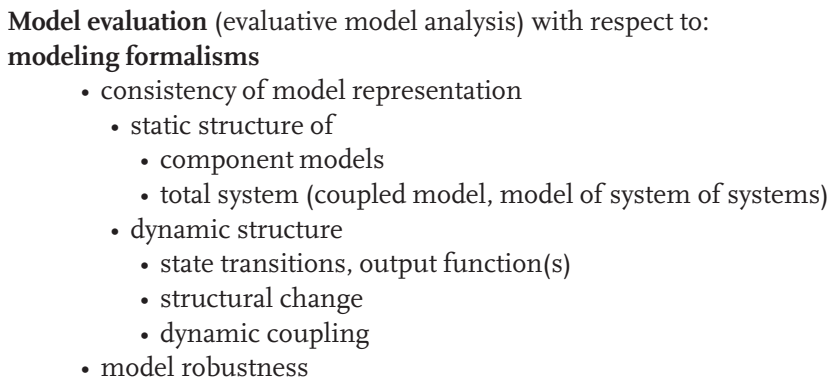

Similarly, verification, as a special type of model evaluation, has several types, as shown in Table 1.16. In this case also, an ontology-based dictionary can display not only the definitions of each of the terms but also their logical relationships.

\subsubsection{Model Transformation}

Model transformation, as shown in Table 1.17, consists of model copying, model reduction, model pruning, model simplification, model elaboration, model isomorphisms, model homomorphisms, and model endomorphisms. 
Table 1.12 Types of model evaluation with respect to another model (comparison).

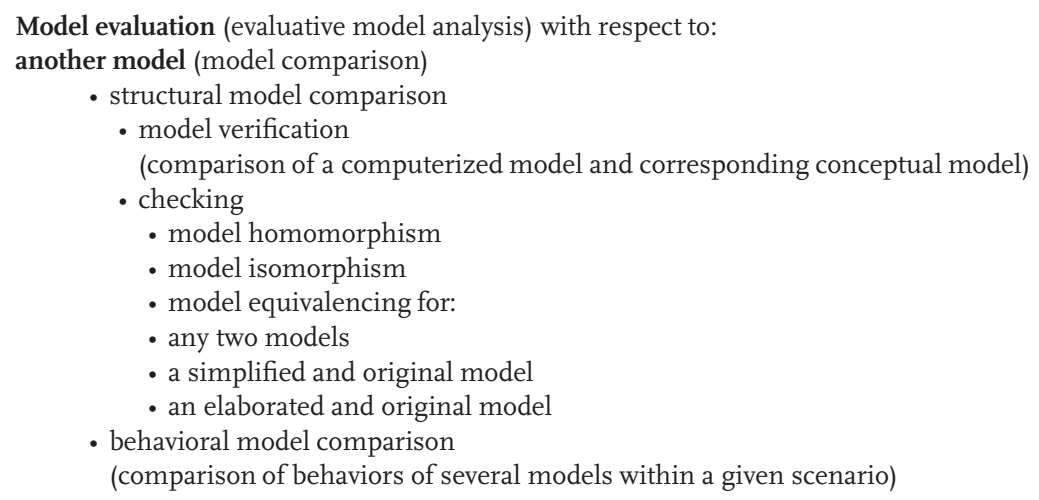

Table 1.13 Types of model evaluation with respect to a real system.

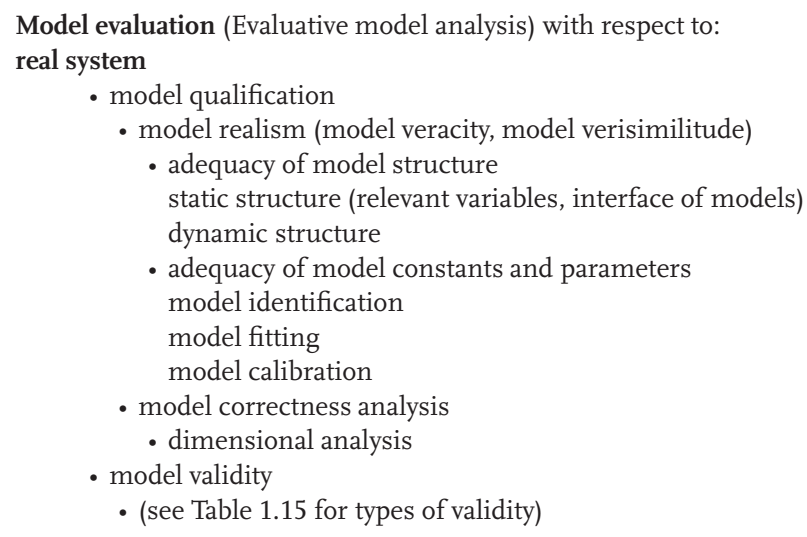

Table 1.14 Types of model evaluation with respect to the goal of study.

Model evaluation (Evaluative model analysis) with respect to: goal of study

- model relevance

- domain of intended application(s) (appropriate use of a model)

- range of applicability of a model

- acceptability of a model with respect to its technical system specification

\subsection{4}

\section{Behavior Generation}

In a simulation process, the model is driven by a behavior generator under experimental conditions to generate the model behavior. Depending on the emphasis, 
Table 1.15 Types of validity.

$\begin{array}{ll}\text { Absolute validity } & \text { Model validity } \\ \text { Conceptual validity } & \text { Multistage validity } \\ \text { Convergent validity } & \text { Operational validity } \\ \text { Cross validity } & \text { Parameter validity } \\ \text { Cross-model validity } & \text { Partial validity } \\ \text { Data validity } & \text { Predictive validity } \\ \text { Dynamic validity } & \text { Predictive model validity } \\ \text { Empirical validity } & \text { Replicative validity } \\ \text { Event validity } & \text { Statistical validity } \\ \text { Experimental validity } & \text { Strict validity } \\ \text { External validity } & \text { Structural validity } \\ \text { Face validity } & \text { Structural model validity } \\ \text { Full validity } & \text { Submodel validity } \\ \text { Gradual validity } & \text { Technical validity } \\ \text { Historical validity } & \text { Theoretical validity } \\ \text { Historical-data validity } & \text { Time-series validity } \\ \text { Hypothesis validity } & \text { Validity } \\ \text { Internal validity } & \text { Variable validity } \\ \text { Logical validity } & \end{array}$

Table 1.16 Types of verification.

Black box verification

Code verification

Correctness verification

Data verification

Design verification

Formal verification

Functional verification

Independent verification and validation

Logical verification

Model verification

Model-based verification

Program verification

Verification

Verification of conceptual model

the behavior generator can also be called the simulation engine or the simulator, as is the case in the terminology used by Zeigler (1984). So long as there is no ambiguity, the choice of the terminology may be immaterial. However, since the term "simulator" is widely used for other devices such as airplane simulators or in 
Table 1.17 Types of model transformation.

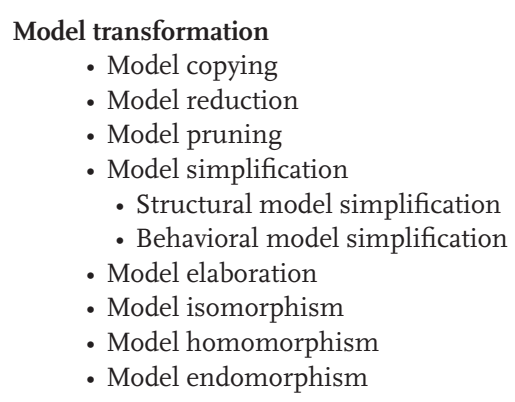

terms such as "virtual simulators", the more descriptive term "behavior generator" is used in this article. There are three types of model behavior: point behavior, trajectory behavior, and structural behavior. Generations of trajectory and structural behaviors correspond to trajectory and structural simulations, respectively. As seen in Table 1.18, behavior can be generated by numerical or nonnumerical techniques. Numerical techniques, especially for continuous models, are treated by Cellier and Kofman (2006). Nonnumerical techniques are used in artificial intelligence applications to $M \& S$.

- Point behavior: This is the behavior of static models, that is, models whose behavior does not depend on time. Experimentation with static models is not simulation. Computation, optimization, and search are examples where the result (behavior) is point behavior. Point behavior can be scalar or $n$ dimensional vector.

- Trajectory behavior: Most simulations belong to this category where trajectories of descriptive variables are generated. At the end of a simulation study, trajectory behavior can be reduced to a performance index. Some possibilities are simulators, several types of simulation, and intermittent simulation such as optimizing simulation and gaming simulation.

- Structural behavior: In some studies, the evolution of the structure of a system can be generated by simulation techniques. Such systems include, for example, growth systems for which L-systems (or Lindenmeyer systems) provide a solid background. Some other applications include, for example, the spread of oil spills, forest fires, epidemics, and rumor.

- Mixed behavior: Some possibilities are mixed trajectory and structural behavior. 
Table 1.18 Types of model behavior and behavior generation.

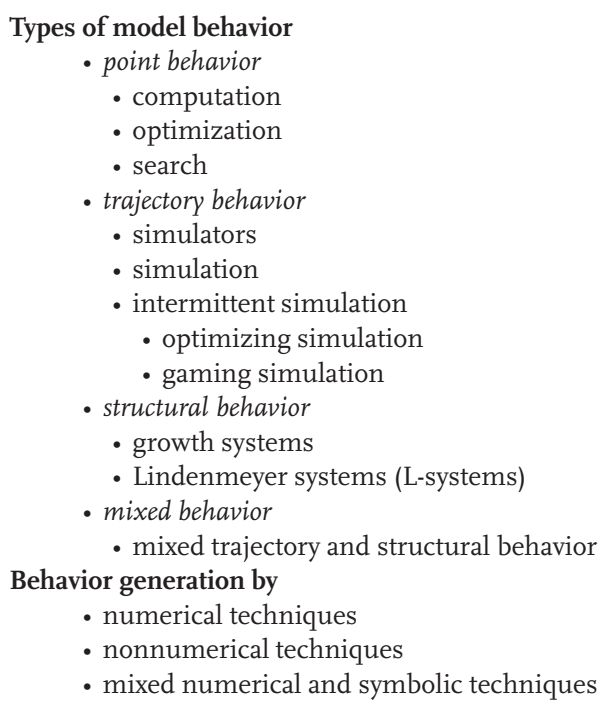

1.4

Synergies of M\&S: Mutual and Higher-Order Contributions

Mutual contributions of M\&S, systems theories, and systems engineering to software engineering, artificial intelligence, and software agents are very important in advanced information technologies. Figure 1.1 depicts these mutual contributions. There are two types of mutual contributions. Tables $1.19-1.23$ outline the direct contributions of $M \& S$, systems theories, systems engineering, software engineering, artificial intelligence, and software agents to each other. Figure 1.1 can also be useful in conceiving higher-order contributions among these disciplines. For example, M\&S contributes to software agents, which in turn can contribute to systems engineering, which can contribute to M\&S. Similarly, several higher-order important contributions can be identified. These positive feedbacks make the mutual contributions even more important.

1.5

\section{Advancement of M\&S}

Due to its tremendous potential, discussions to advance the state of the art of M\&S continue (Yilmaz et al., 2008). A framework for systematic discussion of normative views about the future of M\&S is outlined in Table 1.25 (Ören (2008b)). The last sentence of another article states (Ören, 2002): "Progress in any area is not possible by keeping the status quo no matter how advanced it can be”. Indeed M\&S is 
System

Theories

Software

Agents

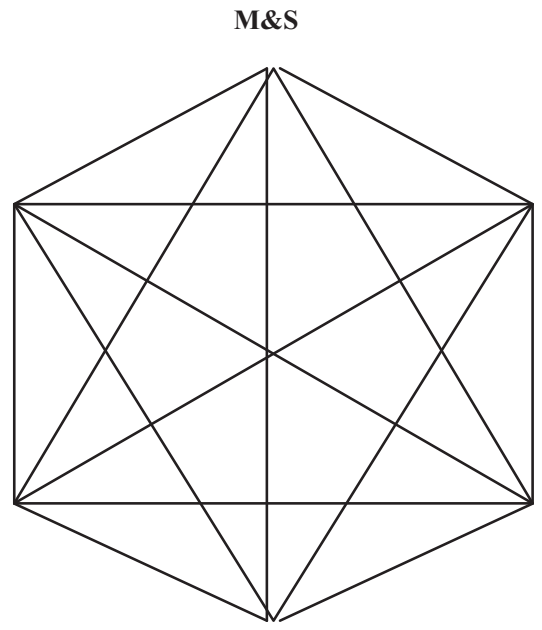

Artificial

Intelligence
Systems

Engineering

Software

Engineering

Fig. 1.1 Mutual contributions of M\&S, systems theories, systems engineering, software engineering, artificial intelligence, and software agents.

Table 1.19 Contributions of M\&S to systems theories, systems engineering, software engineering, artificial intelligence, and software agents.

\section{Contributions of Modeling and Simulation to}

- Systems Theories

- Systems Engineering

- Bases for system design and analyses

- Simulation-based experimentation to test system designs

- Software Engineering

- Model-based software engineering

- Simulation-based tests of software components and systems

- Artificial Intelligence

- Modeling intelligent systems

- Simulation-based testing of intelligent systems

- Software Agents

- Agent simulation (Modeling and simulation of agents)

- Simulation-based testing of agent systems

already very advanced and is also an important, sometimes vital, enabling technology for many areas. However, we ought to continue advancing it for several reasons: (1) to consolidate and disseminate pertinent knowledge about M\&S; (2) to assure professional standards; (3) to advance M\&S science, methodology, and technology to continue solving problems in hundreds of traditional application areas and 
Table 1.20 Contributions of systems theories to M\&S, systems engineering, software engineering, artificial intelligence, and software agents.

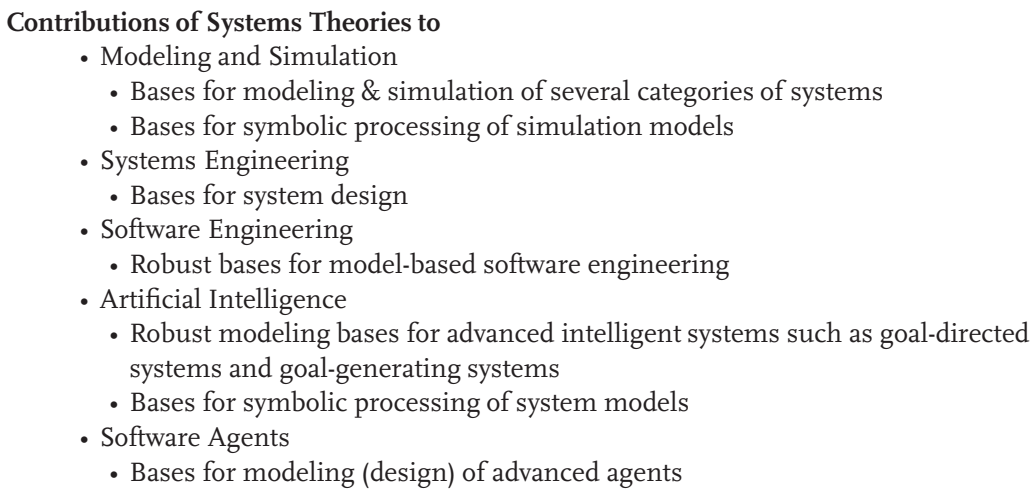

Table 1.21 Contributions of systems engineering to M\&S, systems theories, software engineering, artificial intelligence, and software agents.

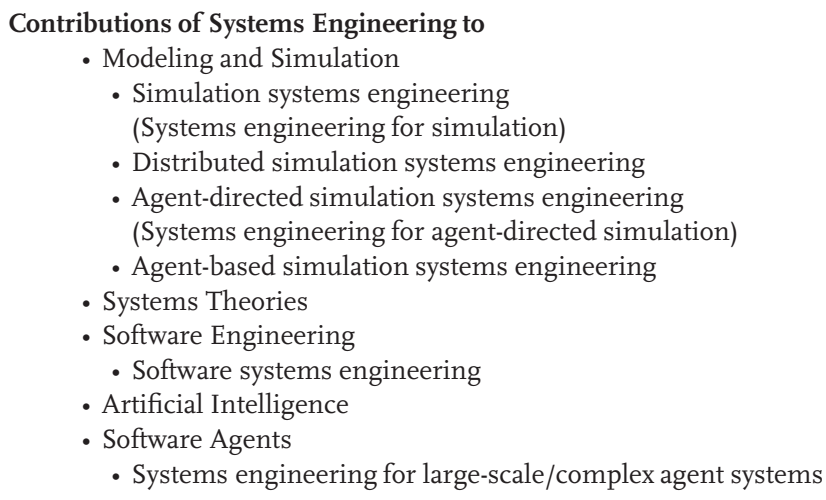

challenging new areas. The framework offered here (which can be elaborated on and refined) may be useful (1) in consolidating and refining the views expressed by advanced users with high expectations as well as by theoreticians, methodologists, and technologists and (2) by systematically monitoring the progress. Some activities would require R\&D; additional activities would include other types of professional and dedicated activities. My (over 100) publications, presentations, and other activities on advanced methodologies and normative views for advancement of M\&S are listed in Ören (2008a).

In the sequel, Table 1.26 summarizes the activities for the consolidation of $M \& S$ knowledge, Table 1.27 outlines the dissemination of M\&S knowledge, Table 1.28 
Table 1.22 Mutual contributions of software engineering to M\&S, systems theories, systems engineering, artificial intelligence, and software agents.

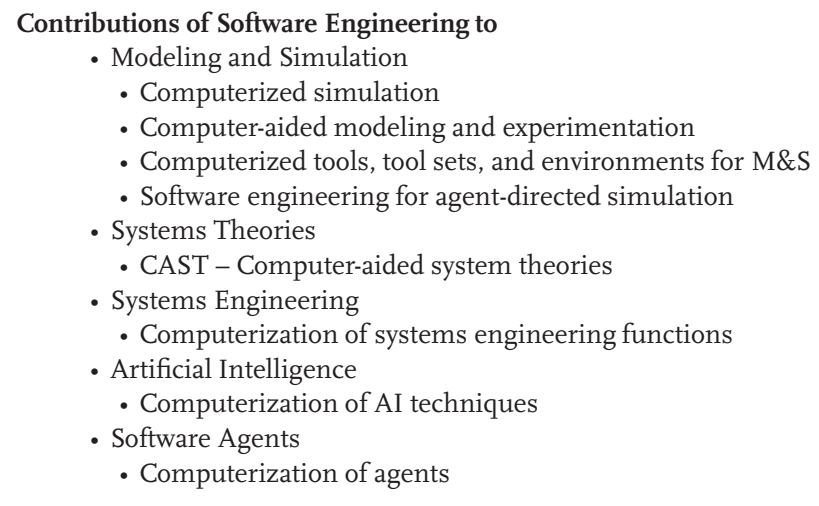

Table 1.23 Contributions of artificial intelligence to M\&S, systems theories, systems engineering, software engineering, and software agents.

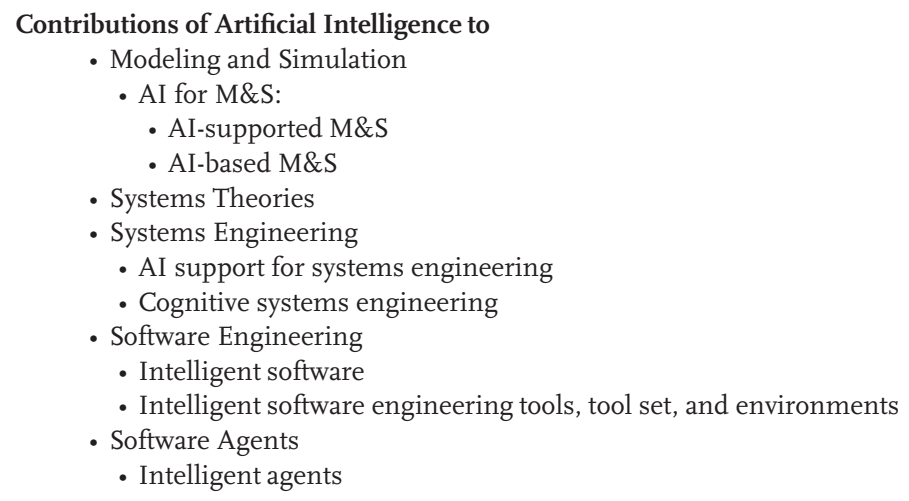

concerns the requirements for professionalism, Table 1.29 elaborates on the science, engineering, and technology of $\mathrm{M} \& \mathrm{~S}$, Table 1.30 is on the trustworthiness, reliability, and quality, and, finally, and Table 1.31 is on more challenging applications. 
Table 1.24 Contributions of software agents to M\&S, systems theories, systems engineering, software engineering, and artificial intelligence.

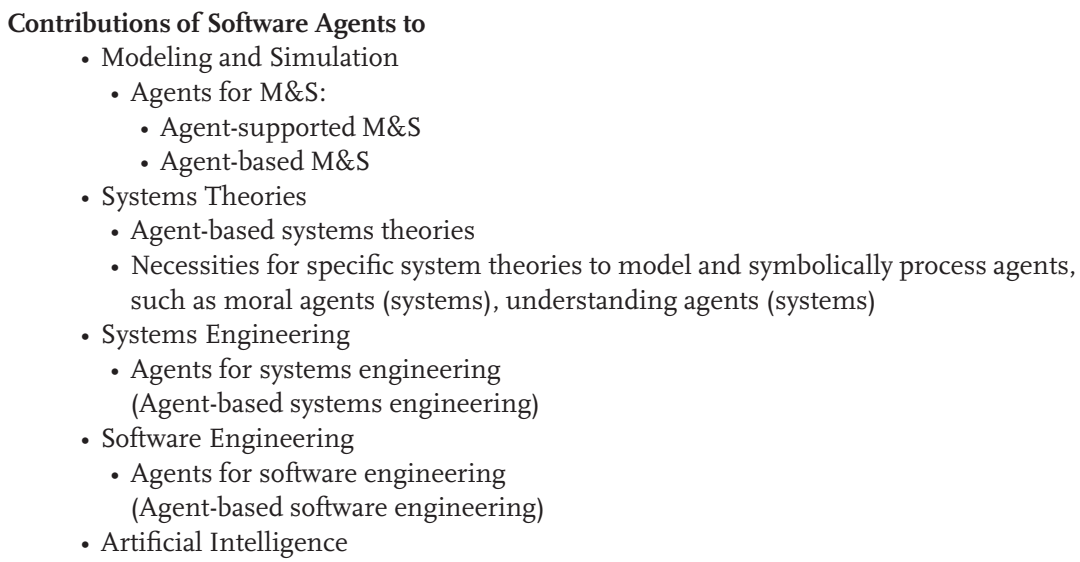

Table 1.25 Categories of advancement areas for M\&S.

Consolidation of M\&S Knowledge

Dissemination of M\&S Knowledge

Requirements of Professionalism

Science, Engineering, and Technology of M\&S

Trustworthiness, Reliability, and Quality

Challenging M\&S Applications

Table 1.26 Consolidation of M\&S knowledge.

Comprehensive view (big picture) of all aspects of $M \& S$

M\&S Body of Knowledge (M\&SBOK):

- Systematization of the index and preparation of a guideline

M\&S Dictionaries

- As inventory of M\&S concepts

- As systematic inventory of M\&S concepts (ontology-based M\&S dictionary)

Curriculum development and international standardization for:

- Degree programs (graduate, undergraduate)

- Service programs for other disciplines

- Professional development courses

\section{6}

\section{Preeminence of M\&S}

Tool making is an essential characteristic of humans or Homo faber "man the toolmaker", as posited by Henri Bergson in L'Evolution Creatrice (Creative Evolu- 
Table 1.27 Dissemination of M\&S knowledge.

(National, Regional, International) e-clearinghouse(s) of:

- Resource libraries

- Funding agencies, funding sources

- Documents of funded research

- Dissertations/theses (as sources of specialists and specialized knowledge)

- Centralized dissemination of professional information (events, job market)

- e-encyclopedia, e-books, M\&S portals

Table 1.28 Requirements of professionalism.

- Ethics: widespread adoption and practice of code of professional ethics (voluntary and/or required for individuals and/or M\&S companies)

- Certification: (voluntary and/or required for individuals and M\&S companies)

- Assesment of maturity levels of individuals and/or companies

- Recognition of the M\&S discipline and profession

- US house resolution 487 (widespread dissemination: nationally, internationally)

- Simulation Systems Engineering needs to be promoted

- Consider analogies with history of dentistry and professional engineering and current status where (uncertified) nonsimulationists doing simulation studies.

- No need to be too humble (consider the use of the term "model" in art and in M\&S as well as simulation-based engineering) (in art "model" designates real-world object!)

Table 1.29 Science, engineering, and technology of M\&S.

Proper system-theory-based modeling and symbolic model processing for simulation of complex systems

Proper simulation paradigms and practices

- Model-based simulation

- Mixed formalism simulation

- Multisimulation

- Concurrent simulation

- Holonic agent simulation for

- Simulation of coopetition (cooperative competition)

- Specification languages/environments for interoperability

- Computer-aided problem solving environments with M\&S abilities

Advanced modeling formalisms and technologies

- With abstraction and descriptive power

- Theory-based modeling formalisms for:

- Variable structure models

- Multimodels

- Multiaspect, multistage, multiperspective, multiresolution, multiparadigm, and evolutionary modeling

Advanced experimentation/scenario generation

- Automation of design \& execution of experiments as well as analyses of results 
Table 1.30 Trustworthiness, reliability, and quality.

- Built-in reliability assurance prior to traditional validation and verification

- Proper computer-aided and computer-processable documentation of simulation studies (including assumptions)

- Taming, monitoring, and assuring software agents in order for agents to behave in a trustworthy way

Table 1.31 Challenging M\&S applications.

- Reduce time of simulation (from conception to generation of alternatives for decision makers)

- Formulate new success metrics

- Applications

- Use of simulation for machine learning

- Use of switchable understanding in simulation (to avoid dogmatic thinking and to assure emotional intelligence)

- Proactive system simulation

- Introspective system simulation

- Simulation of emergent phenomena

- Conflict management simulation

- Security training simulation

- Personality, emotions, and cultural backgrounds in simulation

tion) (Bergson, 1998). In this section, the preeminent position of $M \& S$ in the spectrum of the evolution of tools is presented. The term "tool" has several meanings. For example, the following are selected from the American Heritage Dictionary (AHD-tool, 2008): "1. A device, such as a saw, used to perform or facilitate manual or mechanical work. 2. A machine, such as a lathe, used to cut and shape machine parts or other objects. 3. Something regarded as necessary to the carrying out of one's occupation or profession: Words are the tools of our trade. 4. Something used in the performance of an operation; an instrument: "Modern democracies have the fiscal and monetary tools ... to end chronic slumps and galloping inflations" (Paul A. Samuelson). 5. Computer Science An application program, often one that creates, manipulates, modifies, or analyzes other programs.

Differences of meaning between tool, instrument, implement, utensil, and appliance are as follows.

Tool applies broadly to a device that facilitates work; specifically it denotes a small manually operated device: a box full of tools for bike repair. Instrument refers especially to a relatively small precision tool used by trained professionals: a sterilized scalpel and other instruments. Implement is the preferred term for tools used in agriculture and certain building trades: rakes, hoes, and other implements. Utensil often refers to an implement used in a household, especially in the kitchen: cooking utensils hung by the stove. Appliance most frequently denotes a power-driven de- 
vice that performs a specific function: a store selling toasters and other appliances (AHD-tool, 2008).

To be able to see the preeminent place of M\&S in the spectrum of the evolution of tools, let's consider three categories of tools: (1) physical tools, (2) knowledge-based or soft tools, and (3) knowledge generation tools. For each category, we will consider three levels, namely, manual tools, power tools, and cybernetic tools. Passing from one level to the next requires a critical additional feature. M\&S, being model-based experiential knowledge generation, has a special place among knowledge generation tools.

\subsection{1}

\section{Physical Tools}

The first level of physical tools consists of manual tools including different types of stone and bone tools, metallic tools, mechanical tools, and electronic tools. A very large group of tools and instruments, from a hammer to a doctor's scalpel, or manual typewriters, and scopes including Galileo's telescope, or microscopes fall in the category of manual physical tools.

The second level of physical tools or power tools have access to added energy; hence they have the ability to perform work. They include simple power tools, machine tools, machines (including automotive vehicles), and integrated machines (including transfer machines used in building cars).

The third level of physical tools or cybernetic tools also have a knowledge processing ability. There are two types of knowledge processing machines: machines for knowledge processing and machines with a knowledge processing ability.

- Machines for knowledge processing include (digital) computers. However, there are two other types of machines for knowledge processing depending on whether they are fixed wired tools or machines such as an abacus, astrolabe, and bar-linkage computers. Variable-wired tools/machines for knowledge processing include early punched-card machines (or unit records), as well as analog and hybrid computers.

- Machines with a knowledge processing ability (or computer-embedded systems/machines - CES) benefit from the knowledge processing ability to perform their main goal. Most contemporary digital tools/devices/machines fall in this category. For example, digital cameras, smart buildings, smart roads, and so on. For more detail see Ören (1990).

\subsection{2}

\section{Knowledge-Based or Soft Tools}

Nonphysical tools are knowledge-based or soft tools. They include not only software tools but also other knowledge-based tools. 
Level 1:

Manual tools
Stone tools \& bone tools

Metallic tools

Mechanical tools

Electronic tools
Level 2:

Power tools

(physical power tools)
Energy (ability to perform work)

Additional feature:

Simple power tools

Machine tools

Machines

Integrated machines (transfer machines)

Level 3:

Cybernetic tools

Additional feature:

Knowledge processing ability

Knowledge processing machines

- Computers (tools/machines/systems for knowledge processing)

- Tools/machines/systems with knowledge processing abilities (CES-Computer embedded tools/machines/systems)

Fig. 1.2 Levels of physical tools.

The first level of knowledge-based tools includes software (hand-coded software programs and nonautomated documentation) and any other knowledge-based tools as exemplified in the definitions given in Section 1.6.

Computerization is the added critical feature to realize knowledge-based power tools or knowledge-based soft tools. As far as software is concerned, tools, toolkits, and environments of computer-aided software engineering fall in this category. For other knowledge-based tools, computerization is the key feature. 
Level 1:

Manual tools
Software:

- hand-coded programs

- nonautomated documentation

Other knowledge-based tools

Level 2:

Power tools

(knowledge-based power tools or knowledge-based soft tools)

Knowledge processing ability

Additional feature: (computerization; computational)

Computer-aided software engineering

- tools

- tool kits

- environments

Other types of computerized knowledge-based tools

- eg., computational linguistic

Additional feature:

Advanced knowledge processing ability (AI, agents)

Level 3:

Cybernetic tools

Artificial intelligence/agents in software eng.:

- in software

- in software development/maintenance

$\mathrm{AI} /$ agents in other types of soft tools

$-$

Fig. 1.3 Levels of knowledge-based and soft tools.

Advanced knowledge processing is needed to pass to cybernetics tools. For software engineering, there are two possibilities: AI in software engineering and software agents in software engineering. For other knowledge-based tools, similarly, contributions of AI or software agents are essential. 
Table 1.32 Eight types of knowledge generation.

\begin{tabular}{|c|c|c|c|c|c|c|c|}
\hline & \multicolumn{2}{|c|}{ Model or real system } & \multicolumn{2}{|c|}{ Experimentation } & \multirow{2}{*}{$\begin{array}{l}\text { Knowledge } \\
\text { generation } \\
\text { with }\end{array}$} & \multirow{2}{*}{$\begin{array}{l}\text { Technique } \\
\text { Numerical }\end{array}$} & \multirow[b]{2}{*}{$\begin{array}{l}\text { Non- } \\
\text { numerical }\end{array}$} \\
\hline & $\begin{array}{l}\text { Model- } \\
\text { based }\end{array}$ & $\begin{array}{l}\text { Realsystem- } \\
\text { based }\end{array}$ & Experiential & $\begin{array}{l}\text { Nonexpe- } \\
\text { riential }\end{array}$ & & & \\
\hline 1 & $\checkmark$ & & $\checkmark$ & & $\checkmark$ & & $\checkmark$ \\
\hline 2 & $\checkmark$ & & $\checkmark$ & & $\checkmark$ & $\checkmark$ & \\
\hline 3 & $\checkmark$ & & & $\checkmark$ & $\checkmark$ & $\checkmark$ & \\
\hline 4 & $\checkmark$ & & & $\checkmark$ & $\checkmark$ & & $\checkmark$ \\
\hline 5 & & $\checkmark$ & $\checkmark$ & & $\checkmark$ & & $\checkmark$ \\
\hline 6 & & $\checkmark$ & $\checkmark$ & & $\checkmark$ & $\checkmark$ & \\
\hline 7 & & $\checkmark$ & & $\checkmark$ & $\checkmark$ & $\checkmark$ & \\
\hline 8 & & $\checkmark$ & & $\checkmark$ & $\checkmark$ & & $\checkmark$ \\
\hline
\end{tabular}

\subsection{3}

\section{Knowledge Generation Tools}

As outlined earlier, $M \& S$ can also be perceived as a knowledge generation tool, more specifically as a model-based experiential knowledge generation tool. Hence, M\&S has close affinity with other knowledge generation techniques. This third category of tools includes any knowledge generation tools. However, since the aim, is to point out the important and dominant position of $M \& S$, we concentrate on the relative position of $\mathrm{M} \& \mathrm{~S}$. For the sake of completeness, an outline of the typology of knowledge generation is given in Figure 1.4 and Table 1.32.

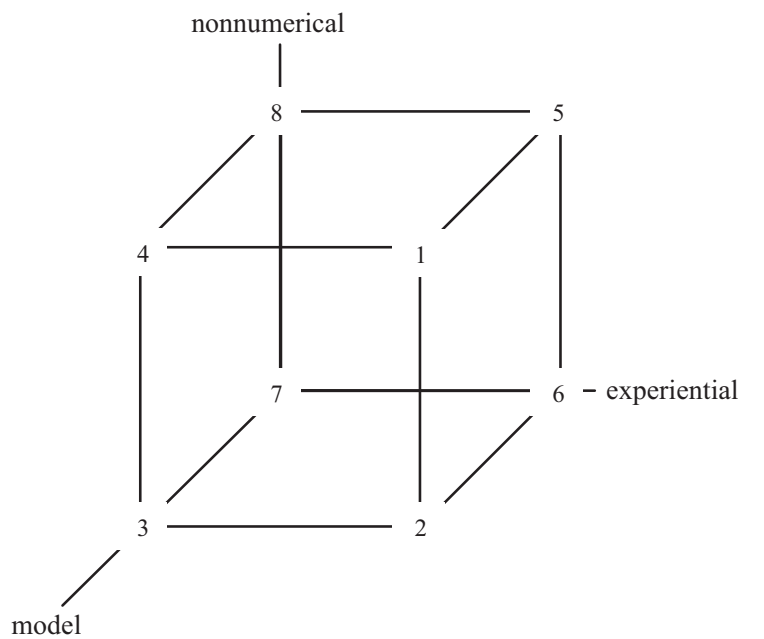

Fig. 1.4 Three dimensions of the typology of knowledge generation. 
Three factors determine the essential characteristics of knowledge generation: (1) knowledge generation is based on a real system or a model, (2) knowledge generation is either experiential or it is not, and (3) the technique is numerical or not. These three dimensions and the eight possibilities are shown in Figure 1.4. The eight types of knowledge generation are as follows (the first two correspond to M\&S). Table 1.32 outlines eight possibilities for knowledge generation.

1. model-based experiential knowledge generation with nonnumerical techniques;

2. model-based experiential knowledge generation with numerical techniques;

3. model-based nonexperiential knowledge generation with numerical techniques;

4. model-based nonexperiential knowledge generation with nonnumerical techniques;

5. real-system-based experiential knowledge generation with nonnumerical techniques;

6. real-system-based experiential knowledge generation with numerical techniques;

7. real-system-based nonexperiential knowledge generation with numerical techniques;

8. real-system-based nonexperiential knowledge generation with nonnumerical techniques.

At the first level, M\&S tools are manual. They include simulation with scale models, sandbox simulations, and any manual simulation. To pass to the second level, computerization is needed. Computerized simulation (or, as it is also called, computer simulation even when the system being simulated is not a computer system) offers a gamut of possibilities from the generation of model behavior to simulation-based comprehensive problem-solving environments. Several tools, toolkits, and environments exist for computer-aided M\&S, including problem specification, modeling, model-base management, design and execution of experiments, and analysis and visualization of results.

An advanced knowledge processing ability (i. e., artificial intelligence or software agents) is necessary to achieve the third level (or cybernetic) of M\&S tools. AIdirected and agent-directed simulations are realized with the synergy of M\&S with $\mathrm{AI}$ and agents, respectively.

- AI-directed simulation consists of simulation of intelligent entities, AIsupported simulation, and AI-based simulation (Ören, 1994, 1995).

- As is clarified in this volume, agent-directed simulation consists of agent simulation, agent-supported simulation, and agent-based simulation. 


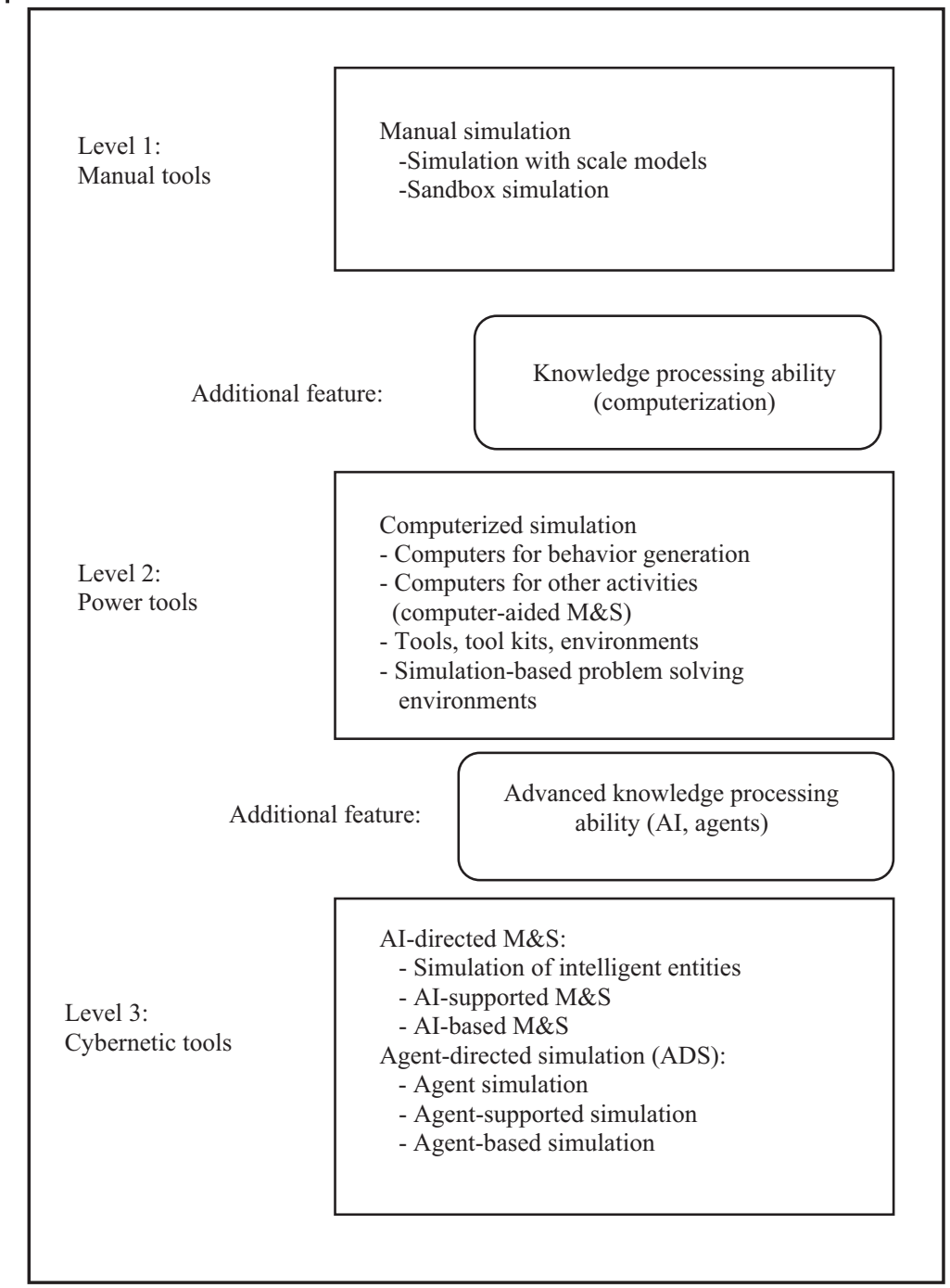

Fig. 1.5 Levels of M\&S tools (model-based experiential knowledge-generation tools).

\section{7}

\section{Summary and Conclusions}

A comprehensive and integrative view of modeling and simulation (M\&S) is offered to those interested in seeing the consolidated big picture and benefiting from all aspects of $M \& S$. To this end, $M \& S$ is considered from five perspectives as follows: (1) purpose of use, that is, experiments (for decision support, understanding, and education); experience (for three types of training and entertainment); and imitation; (2) problem to be solved; (3) connectivity of operations of simulation and 
a real system; (4) M\&S as a type of knowledge processing (i. e., M\&S as a computational activity, systemic activity, model-based activity, knowledge generation activity, and knowledge processing activity); (5) from the perspective of philosophy of science. Afterwards, model-based activities are clarified under the following headings: (1) model building, (2) model-base management, and (3) model processing. The latter is covered under descriptive and evaluative model analyses, model transformation, and model generation. Important synergies of M\&S with system theories, systems engineering, software engineering, artificial intelligence, and software agents are outlined under mutual contributions as well as higher-order contributions. The M\&S discipline is already in its maturing phase (Ören, 2005). The preeminence of $M \& S$ is explained by outlining the special place of M\&S in the spectrum of the evolution of tools. The similarity concept, which is the foundation of simulation, offers a rich paradigm. An appendix of over 80 terms besides simulation with similarity connotations is also given. These terms show the richness of the concept of similarity and can be useful in languages other than English in selecting/suggesting equivalent terms.

\section{Appendix}

Tab. 1.A.1: Concepts other than simulation with similarity connotation.

\begin{tabular}{lll}
\hline analog & dissimilatory & imitative \\
analogic & dissimilitude & isomorph \\
analogical & dissimulate (v) & isomorphic \\
analogous & dissimulated & isomorphism \\
analogy & dissimulating & isomorphous \\
assimilate (v) & dissimulation & like \\
assimilated & dissimulator & likeness \\
assimilation & emulate (v) & metaphor \\
autosimulation & emulated & metasimulation \\
autosimulative & emulating & nonsimulatable \\
bisimular & emulation & pataphor \\
bisimulate (v) & emulative & replica \\
bisimulation & emulator & resemblance \\
comparable & endomorph & self-similar \\
comparative & endomorphic & similar \\
compare (v) & endomorphism & similarity \\
comparison & endomorphous & similitude \\
congruent & homology & simulacra \\
congruence & homomorph & simulacre \\
congruity & homomorphic & simulacrum \\
\end{tabular}




$\begin{array}{lll}\text { congruous } & \text { homomorphism } & \text { simuland } \\ \text { copy (v) } & \text { homomorphous } & \text { simulatable } \\ \text { cosimulation } & \text { homothetic } & \text { simulate (v) } \\ \text { cosimulative } & \text { homothetism } & \text { simulated } \\ \text { differentiation } & \text { homothety } & \text { simulating } \\ \text { dissimilar } & \text { hyperreality } & \text { simulationist } \\ \text { dissimilarity } & \text { imitate (v) } & \text { simulative } \\ \text { dissimilation } & \text { imitate (v) } & \text { simulator } \\ \text { dissimilator } & \text { imitation } & \text { symbol }\end{array}$

\section{References}

AHD-tool (2008) The American Heritage Dictionary, http://www.bartleby.com/61/62/ T0266200.html (accessed 4 December 2008).

Baudrillard, J. (1985) Simulacres et Simulation (original in French). Translation in English: Simulacra and Simulation, The University of Michigan Press.

BD (2008) Business Dictionary, http:// www.businessdictionary.com/definition/ computer-simulation.html. (accessed 3 December 2008).

Bell, D. (1976) Welcome to Post-Industrial Society. Physics Today.

Bergson, H. (1998) L'Evolution Creatrice. (Creative Evolution, translated by Arthur Mitchell), Dover, New York.

Cellier, F.E. and Kofman, E. (2006) Continuous System Simulation, Springer, Norwell, MA.

Elzas, M.S., Ören, T.I., Zeigler, B.P. (1986) Modelling and Simulation Methodology in the Artificial Intelligence Era, North-Holland, Amsterdam, p. 423.

Elzas, M.S., Ören, T.I., Zeigler, B.P. (1989) Modelling and Simulation Methodology: Knowledge Systems Paradigms, NorthHolland, Amsterdam, p. 487.

HR 487 (2008) U.S. Senate House Resolution 487, http://thomas.loc.gov/cgi-bin/query/ Dc110:1/temp/c110wpVyNH (accessed 3 December 2008).

Mathewson, C.S. (1974) Simulation program generators. Simulation, 23 (6), 181-189.

M\&S-AO (2008) Modeling and Simulation Associations and Organizations, http://www. site.uottawa.ca/ oren/links-MS-AG.htm (accessed 3 December 2008).
mc-swEng (2008) Model-centric Software Engineering, http://3m4mda.telin.nl/ (accessed 4 December 2008).

md-EIS (2008) Model-driven Enterprise Information Systems, http://www.iceis.org/ workshops/mdeis/mdeis2007-cfp.html (accessed 4 December 2008).

Nance, R.E. (1983) A Tutorial View of Simulation Program Development. Technical Report CS83025-E. Virginia Polytechnic Institute and State University, Blacksburg, VA. An invited presentation for the 1983 Winter Simulation Conference, Washington, DC.

NATO-MP-v1.0 (2008) NATO Modelling and Simulation Master Plan, version 1.0, AC/323 (SGMS)D/2, ftp://ftp.rta.nato. int/Documents/MSG/NMSMasterPlan/ NMSMasterPlan.pdf (accessed 3 December 2008).

OED-sim (2008) Online Etymology Dictionary, http://www.etymonline.com/index.php? term=simulation (accessed 3 December 2008).

OED-simulacrum (2008) Online Etymology Dictionary, http://www.etymonline.com/ index.php? search=simulacrum (accessed 3 December 2008).

O'Haver, T. (2008) Simulations and Computer Models in the Classroom, http://terpconnect. umd.edu/ toh/simulations.html (accessed 3 December 2008).

Oldfather, M.P., Ginsberg, S.A. and Markowitz, M.H. (1966) Programming by Questionnaire: How to Construct a Program Generator. RAND Report RM-5129$P R$. 
Ören, T.I. (1971) GEST: A Combined Digital Simulation Language for Large-Scale Systems. Proceedings of the Tokyo 1971 AICA (Association Internationale pour le Calcul Analogique) Symposium on Simulation of Complex Systems, September 3-7, 1971, Tokyo, Japan, pp. B-1/1-B-1/4.

Ören, T.I. (1982) Computer-Aided Modelling Systems, in Progress in Modelling and Simulation, (ed. F.E. Cellier), Academic Press, London, England, pp. 189-203.

Ören, T.I., Zeigler, B.P. and Elzas, M.S. (1984) Simulation and Model-Based Methodologies: An Integrative View, Springer-Verlag, Berlin, Heidelberg, New York, Tokyo.

Ören, T.I. (1984a) GEST - A Modelling and Simulation Language Based on System Theoretic Concepts, in Simulation and Model-Based Methodologies: An Integrative View (eds T.I. Ören, B.P. Zeigler, M.S. Elzas), Springer-Verlag, Heidelberg, Germany, pp. 281-335.

Ören, T.I. (1984b) Model-Based Activities: A Paradigm Shift, in Simulation and ModelBased Methodologies: An Integrative View, (eds T.I. Ören, B.P. Zeigler, M.S. Elzas), Springer-Verlag, Heidelberg, Germany, pp. 3-40.

Ören, T.I. (1990) A Paradigm for Artificial Intelligence in Software Engineering, in Advances in Artificial Intelligence in Software Engineering, vol. 1 (ed. T.I. Ören), JAI Press, Greenwich, Connecticut, pp. 1-55.

Ören, T.I. (1991) Knowledge-Based Simulation: Methodology and Application, in Knowledge-Based Simulation: Methodology and Application, (eds P.A. Fishwick and R.B. Modjeski), Springer-Verlag, Berlin, Heidelberg, New York, Tokyo, pp. 53-76.

Ören, T.I. (1994) Artificial intelligence and simulation. Annals of Operations Research, 53, 287-319.

Ören, T.I. (1995) Artificial Intelligence and Simulation: A Typology. Proceedings of the 3rd Conference on Computer Simulation, (ed. S. Raczynski), Nov. 15-17, Mexico City, pp. 1-5.

Ören, T.I. (2002) Future of Modelling and Simulation: Some Development Areas. Proceedings of the 2002 Summer Computer Simulation Conference, pp. 3-8.

Ören, T.I. (2005) Maturing Phase of the Modeling and Simulation Discipline. Proceedings of: ASC - Asian Simulation Conference 2005, (The Sixth International Conference on System Simulation and Scientific Computing (ICSC' 2005)), October 24-27, Beijing, P.R. China, International Academic Publishers - World Publishing Corporation, Beijing, P.R. China, pp. 72-85.

Ören, T.I. (2008) Ontology-Based MQS Dictionaries: An Example for $V \& V$, http: //www.site.uottawa.ca/ oren/MSBOK/ terms-ob-VV.htm (accessed 4 December 2008).

Ören, T.I., Ghasem-Aghaee, N. and Yilmaz, L. (2007) An Ontology-Based Dictionary of Understanding as a Basis for Software Agents with Understanding Abilities. Proceedings of the Spring Simulation Multiconference (SpringSim'07), March 25-29, Norfolk, VA.

Ören, T.I. (2008a) List of Publications, Presentations and Other Activities on Normative Views for Advancements of MeS, http: //www.site.uottawa.ca/ oren/pubsList/ MS-advanced.pdf (accessed 4 December 2008a).

Ören, T.I. (2008b) A Framework for Desirable Activities and Research in M\&S. Part of the Position Statements for the Panel Discussion (ed. L. Yilmaz) What Makes Good Research in Modeling and Simulation: Sustaining the Growth and Vitality of the MaJS Discipline.Proceedings of the 2008 Winter Simulation Conference, pp. 677-689, Miami, FL, 2008.

Ören, T.I. (2009) Uses of Simulation, in Principles of Modeling and Simulation: A Multidisciplinary Approach, (eds J.A. Sokolowski and C.M. Banks). John Wiley and Sons, Inc. New Jersey, 153-179.

SCS (2008) Society for Modeling and Simulation International, http://www.scs.org/ AboutSCS.cfm (accessed 3 December 2008).

SEP-Baudrillard (2008) Stanford Encyclopedia of Philosophy, http://plato.stanford.edu/ entries/baudrillard (accessed 3 December 2008).

SEP-postmodernism (2008) Stanford Encyclopedia of Philosophy, http://plato.stanford. edu/entries/postmodernism (accessed 3 December 2008).

Pritsker, A.A.B. (1979) Compilation of Definitions of Simulation. Simulation, 33 (2), 61-63. 
sim4Ed (2008) Simulation in Education and Training, http://www.site.uottawa.ca/ oren/MSBOK/sim4Ed.htm (accessed 3 December 2008).

simDef-SECO (2008) DND/CF Modelling Q Simulation/Synthetic Environments Lexicon, http://www.drdc-rddc.gc.ca/seco/ documents/MSLexiconApr02e.html (accessed 3 December 2008).

SimDefsWeb (2008) Simulation Definitions on Web. http://www.google.ca/search? source= definition+simulation (accessed 3 December 2008).

SimDefsWeb (2008) Simulation, Training, and Instrumentation, http://www.globalsecurity. org/military/agency/army/stricom.htm (accessed 3 December 2008).

US-DHaHS (2008) US Department of Health and Human Services - Administration for Children \& Families, http: //www.acf.hhs.gov/programs/cb/systems/ sacwis/cbaguide/appendixb.htm (accessed 3 December 2008).

Wymore, W.A. (1967) A Mathematical Theory of Systems Engineering: The Elements. Krieger, Huntington, NY.

Wymore, W.A. (1993) Model-Based Systems Engineering. CRC Press, Boca Raton.

Yilmaz, L., Davis, P., Fishwick, P., Hu, X., Miller, J.A., Hybinette, M., Ören, T.I., Reynolds, P., Sarjoughian, H. and Tolk, A. (2008) What Makes Good Research in Modeling and Simulation: Sustaining the Growth and Vitality of the MQS Discipline. Proceedings of the 2008 Winter Simulation Conference, Miami, FL, pp. 677-689.

Zeigler, B.P., Elzas, M.S., Klir, J.G. and Ören, T.I. (1979) Methodology in System Modelling Q Simulation, North-Holland, Amsterdam, p. 537.

Zeigler, B.P. (1984) Multifacetted Modelling and Discrete Event Simulation, Academic Press. 